\title{
Seismogenesis and State of Stress in the UK
}

\author{
B. Baptie ${ }^{\mathrm{a}, *}$ \\ ${ }^{a}$ British Geological Survey, Murchison House, West Mains Road, Edinburgh, U.K.
}

\begin{abstract}
In this paper I present a compilation of focal mechanisms for earthquakes with magnitudes greater than $3.0 M_{L}$ in the British Isles that can be used to help constrain our understanding of seismicity and it's driving forces in the British Isles. The fault plane solutions consist of both previously published mechanisms for significant British earthquakes, and new solutions calculated from regional and local data for more recent and smaller earthquakes that were previously unpublished. Focal mechanisms for earthquakes in the UK are dominantly strike-slip with northwest-southeast compression and northeast-southwest tension, or reverse, with northwest-southeast compression. In many cases there is also an oblique component to the slip. P and $\mathrm{T}$ axes from individual solutions are relatively well constrained in azimuth, though less so in dip, with P-axes orientation for most events clustering between north and north-west, indicating sub-horizontal compression. However, some spatial variation in $\mathrm{P}$ - and $\mathrm{T}$-axes orientation is also apparent, with near north/northeast compression and east-west extension in northwest Scotland, changing to northwest-southeast compression in England and Wales.
\end{abstract}

\footnotetext{
${ }^{*}$ Corresponding author

Email addresses: bbap@bgs.ac.uk (B. Baptie) 
I estimate a best-fitting stress tensor, under the assumption of uniform stress using two different inversion methods for both the entire focal mechanism data set and two different subsets of the data. The results from the two different datasets suggest that there is a significant difference in the stress state between northwest Scotland and England and Wales. Calculated $\sigma_{1}$ directions for England and Wales are northwest-southeast, consistent both with existing stress data and expected stresses from first order plate motions. By contrast, the inversion results for northwest Scotland show near east-west extension with possible $\sigma_{1}$ and $\sigma_{2}$ directions lying in a north south band, and that the magnitudes of $\sigma_{1}$ and $\sigma_{2}$ are similar. The relative magnitude of the principal stresses, $R$, determined for England and Wales suggests that the intermediate stress $\sigma_{2}$ is close to the average value of $\sigma_{1}$ and $\sigma_{3}$.

The clear difference in the stress inversion results between northwest Scotland and England and Wales suggests that the principal stress directions expected from first order plate motions have been modified in Scotland by local stress conditions due to glacio-isostatic adjustment.

Key words: , British Isles, earthquakes, Focal mechanisms, stress

\section{Introduction}

The underlying cause and distribution of earthquake activity in the British

Isles is not clearly understood. Main et al. (1999) suggest that the observed 4 neotectonic uplift combined with a direction of maximum (regional) stress 5 deduced from earthquake focal mechanisms supports the theory that defor6 mation is dominated by glacio-isostatic recovery. More recently, Bott and 7 Bott (2004) and Arrowsmith et al. (2005) argue the earthquake activity is 
1

a response to an underlying hot, low-density anomaly in the upper mantle. Earthquake source mechanisms provide both fault geometries and principal stress directions that can be used to constrain our understanding of the driving forces of current deformation. However, unlike plate boundaries, where stress regimes are generally straightforward, intra-continental areas have often been subject to multiple episodes of deformation, the driving forces of deformation are less obvious. Furthermore, because of low seismicity rates, the number of reliable focal mechanisms may be limited. To improve our understanding of the driving forces for earthquakes in the British Isles we need to increase the number of earthquake source mechanisms that can be used for seismotectonic interpretation by extending analyses to earthquakes of lower magnitude than is common in such studies. Previously published focal mechanisms for UK earthquakes are relatively rare and are generally limited to the infrequent events of $M_{L}>4.5$. King (1980) determined a fault plane solution for the magnitude $4.8 M_{L}$ Carlisle earthquake of 1979. Assumpçao (1981) calculated a composite fault plane solution for the 1979 earthquake swarm in NW Scotland. Turbitt et al. (1985) and Trodd et al. (1985) calculated independent estimates of the focal mechanism of the magnitude 5.4 $M_{L}$ Lleyn Peninsula earthquake in 1984 using local and teleseismic data respectively. Both solutions are in general agreement. Ritchie et al. (1990) calculate a focal mechanism for the magnitude 5.0 $M_{L}$ Bishops Castle earthquake, 1990. More recently, Heyburn et al. (2005) and Baptie et al. (2005) present focal mechanisms for the magnitude $4.7 M_{L}$ Dudley earthquake, 2002, calculated from regional and local observations respectively. Ottemöller et al. (2009) compute a moment tensor for the $4.0 M_{W}$ 
1 Folkestone earthquake of 2007.

2 It is well known that the axes of minimum and maximum compression 3 for a given fault plane solution may vary significantly from the principal 4 stress directions, as slip generally occurs on a pre-existing zone of weakness 5 (McKenzie , 1969). As a result the principle stress directions are poorly 6 constrained by a single fault-plane solution. However, groups of focal mech7 anisms within a region of uniform stress can be used to obtain a measure of 8 both stress directions and also the relative magnitude of the stresses, for ex9 ample Gephart and Forsyth (1984). Numerous techniques exist that can be 10 used to determine stress fields from fault orientation and slip direction data. 11 Angelier (1984) uses a non-linear inversion method to estimate principal 12 stress directions from fault slip data. Michael (1987) uses a linear inversion method. Gephart and Forsyth (1984) use a grid search method to invert for the stress field. Marrow and Walker (1988) used the graphical, right dihedra

method of Angelier et al. (1984) with focal mechanisms for five UK earthquakes to find a near horizontal, northwest-southeast maximum compressive stress, $\sigma_{1}$ and northeast-southwest $\sigma_{3}$. Lisle (1992) used an extension of the same method and an additional focal mechanism to find a $\sigma_{1}$ axis that plunges at an angle of 48 towards 328. However, both these studies use only a small number (six or less) of previous published fault plane solutions as input data for their studies.

The first aim of this paper is to present a compilation of focal mechanisms derived for the small to moderate earthquakes typically observed in the British Isles that can then be used to help constrain our understanding of the present data stress field and crustal deformation. I compile focal 
1

2 The fault plane solutions consist of both previously published mechanisms

3 for significant British earthquakes, for example Ottemöller et al. (2009) and

4 new solutions calculated from local recorded data for more recent and smaller

5 earthquakes that were previously unpublished. The second aim is to estab-

6 lish if these fault plane solutions can be explained by a single stress tensor

7 orientation, i.e. homogeneous stress field, or if there are spatial variations in

8 the stress tensor orientation across the British Isles. I test this hypothesis by

9 inverting the focal mechanism data to estimate a best-fitting stress tensor,

10 under the assumption of uniform stress. Two different methods of stress ten-

sor inversion are used (Gephart and Forsyth , 1984; Michael , 1987), which each give different estimates of misfit. I examine spatial variations in stress tensor orientation by dividing the data into two regional subsets.

\section{Local Seismicity and Tectonic History}

Figure 1 shows both instrumental seismicity (1970-present) for earthquakes with $M_{L}>2.0$ and historical seismicity (pre-1970) for earthquakes with $M_{L}>3.0$ taken from the British Geological Survey (BGS) earthquake catalogue (Musson , 1996). There are relatively strong variations in the spatial distribution of seismicity throughout the UK. In general earthquakes occur in a north south band along the length of Britain, mainly along the western flank. This band gets wider moving south. The northeast of Britain, the northwest Atlantic margin and Ireland all show an absence of notable seismicity. The earthquake band on the UK mainland cuts through the geological terrane boundaries, also shown in Figure 1, most of which run 
northeast southwest. Onshore activity is quite distinct from the seismic activity in the North Sea rift zone. Historical evidence shows that significant earthquakes can affect the south and east of the UK, but until the Folkestone earthquake in 2007 there was little instrumental evidence for such events. In Scotland, a correlation between the spatial extent of seismcity and the expected area of maximum glacio-isostatic uplift has been noted by a number of authors, including Musson (1996). No British earthquake recorded either historically or instrumentally has produced a surface rupture and typical fault dimensions for the largest recorded British earthquakes are of the order of 1-2 km, therefore, it is difficult to accurately map earthquakes to specific faults, particularly at depth, where the fault distributions and orientations are unclear, given the large uncertainties involved. However, a number of studies, for example Ottemöller and Thomas (2007), use the alignment of earthquakes from a specific sequence, along with fault plane solutions, to identify causative faults.

The UK lies on the northwest European shelf at the northeast margin of the North Atlantic Ocean. Its continental crust formed over a long period of time and has a complex tectonic history, which has produced much lateral and vertical heterogeneity through multiple episodes of deformation (Woodcock and Strachan , 2000). Reconstructions of plate motions show that during the Phanerozoic the northern part of the British Isles was located at the passive margin of Laurentia, while the southern part was located at the subducting margin of Avalonia. North of the Highland boundary fault the crust is Laurentian, while South of the Iapetus Suture Zone in England and Wales the crust is Avalonian. The closure of the Iapetus Ocean during the 
Caledonian Orogeny (460-420 Ma) then resulted in the juxtaposition of the two, separated by an intermediate accreted zone in between. Bluck et al. (1992) divides the British Isles into a number of fault-bounded basement blocks or terranes. The amalgamation of these terranes during the Caledonian Orogeny affected an the area extending from the Moine Thrust in the northwest to the Welsh Caledonides in the south, resulting in a dominant structural trend that is approximately northeast-southwest. A wedge-shaped basement block of Proterozoic crust called the Midlands Platform dominates much of Southern Britain (Pharaoh et al., 1993), and is terminated by the Variscan Front to the south and Welsh Caledonides to the North. Structures trend northeast in the western part but northwest in the eastern part. South of the Variscan Front are the strongly deformed Palaeozoic rocks of southern Britain. Structure in the fold belt is generally east/southeast.

\section{Focal Mechanisms}

The focal mechanisms used in this study consist of both previously published fault plane solutions for significant British earthquakes, and new solutions calculated from local data for smaller earthquakes that were previously unpublished. In total, I use eleven previously published focal mechanisms, which are mainly limited to infrequent larger events of $M_{L}>4.5$. The mechanisms for these events have been calculated in a number of ways including from first motion polarities, teleseismic observations and moment tensor inversion. These solutions are listed in Table 1 along with references.

To increase the number of events available for analysis, I also calculated focal mechanisms for additional earthquakes with a local magnitude of 3.0 
$1 M_{L}$ and above using first motion polarities and the grid search method of 2 Snoke et al. (1984). Moment tensor inversion is not possible for these events, 3 mainly because such earthquakes do not release sufficient long period seismic 4 energy, but also because of a lack of broadband seismic data for the older 5 events.

6 In areas of low seismicity and sparse station distribution, determining reliable focal mechanisms can be problematic. However, the number of stations s in the UK is relatively high, so it is generally possible to find a reasonable

number of observations of P-wave first motion with a good azimuthal distribution at different epicentral distances for earthquakes with a local magnitude of $3.0 M_{L}$ and above. There are generally around three earthquakes of this size annually in the UK and a search of the British Geological Survey (BGS) earthquake catalogue reveals that there are 126 instrumentally recorded events in mainland UK with $M_{L}>3.0$ since 1970. Fifty-one of these events are prior to 1980, when instrumental coverage was poor, so calculation of a focal mechanism is generally not possible, except for events such as Carlisle, 1979 and Kintail, 1974.

Fault plane solutions were calculated for all the remaining 64 earthquakes without mechanisms using the grid search method of Snoke et al. (1984). The grid search results in a number of solutions that fit the observed directions of ground motion and amplitudes at each station. Only well constrained solutions with more than ten polarity readings and standard deviations of less than $40^{\circ}$ in the strike, dip and rake were used in this study. This gave twenty mechanisms where both focal planes were well constrained, for subsequent interpretation and analysis. Stereographic plots for these events showing the 
first motion polarities used to determine the solutions are shown in Figure 2. The solutions are also listed in Table 1.

Focal mechanisms for all events are shown in Figure 3. The resulting fo4 cal mechanisms for England and Wales are mainly strike-slip with northwest-

southeast compression and northeast-southwest tension, or reverse, with northwestsoutheast compression. In many cases there is also an oblique component to the slip. This results in dips for the $\mathrm{P}$ axes that are sub-horizontal, while the $\mathrm{T}$ axes vary from horizontal to vertical. The P-axes orientations for most events cluster between north and northwest. Significant anomalies from this trend are the two Bargoed earthquakes in 2001 and 2002, which both show normal faulting. These events are located in an area of considerable mining activity. This, combined with the shallow focal depths suggests that there is a strong possibility that they are caused by mining related stress changes. For this reason, these events are omitted from subsequent analysis. The largest of the aftershocks $\left(4.3 M_{L}\right)$ from the 1984 Lleyn earthquake $\left(5.4 M_{L}\right)$ also shows normal faulting, whereas the mainshock is oblique strike slip, although with a significant normal component. The ternary diagram in Figure 4 shows the amount of oblique slip for each earthquake. Although most of the events have strike-slip mechanisms, many of these include significant amounts of normal slip, while a few show reverse components. Events with significant normal components include Dunoon (1986), Shrewsbury (1996), Sennybridge (1999), Aberfoyle (2003) and Folkestone (2007).

Focal mechanisms for the five earthquakes in northwest Scotland show significant differences from those in England and Wales with near north-south P-axes orientations and east-west T-axis orientations. The focal mechanism 
1

for the Aberfoyle event determined by Ottemöller and Thomas (2007) is even further rotated and has a P-axis orientation that approaches southwestnortheast.

\section{Continuity of Stress}

I estimate a best-fitting stress tensor for the UK by inverting all the focal mechanism data under the assumption of uniform stress. Two different methods of stress tensor inversion are used: the FMSI method of Gephart and Forsyth (1984); and the LSIB method of Michael (1987). Since each focal mechanism has two possible fault planes and slip directions, both methods also attempt to distinguish between the fault plane and the auxiliary plane. All solutions are given equal weighting in each inversion.

Given a population of earthquake focal mechanisms, the FMSI method of Gephart and Forsyth (1984) uses a grid search of possible stress models to find the model that requires the smallest total rotation of all fault planes required to match the observed and predicted slip. The method also allows identification of the more likely of the two possible fault planes, i.e. the one that requires the least rotation. There are two main assumptions, firstly that the stress tensor is uniform within the crustal volume investigated, and secondly, that slip on each fault occurs in the direction of maximum resolved shear stress (Bott , 1959). The relative magnitude of the principal stresses is given by the parameter $\left.R=\left(\sigma_{3}-\sigma_{1}\right) / \sigma_{2}-\sigma_{1}\right)$.

The LSIB inversion method of Michael (1987) linearizes the stress inversion problem by assuming that the maximum resolved shear stress on the fault plane is parallel to the slip direction, with additional constraints on its 
1

magnitude to ensure that the traction is sufficient to cause faulting. Confidence regions are determined using a bootstrap technique, in which the data are resampled hundreds or thousands of times. Here, I use 2000 resamples.

The relative magnitude of the principal stresses is also given by a parameter $\left.R=\left(\sigma_{2}-\sigma_{3}\right) / \sigma_{1}-\sigma_{3}\right)$.

Inversion results for the whole data set using both methods are listed in Table 2. Orientations of the best-fitting principal stresses are given by trend and plunge angles. Also shown is the overall misfit and the direction of the maximum horizontal compressive stress, $s_{H}$, calculated following Lund and Townend (2007). The azimuths of the principal stresses given by both methods are reasonably similar, however the LSIB method gives dips that are much closer to horizontal. The values of $R$ given by each method suggests that the intermediate stress $\sigma_{2}$ is close to the average value of $\sigma_{1}$ and $\sigma_{3}$. This gives a triaxial stress ellipsoid that is stretched along a horizontal axis, with $\sigma_{1}>\sigma_{2}>\sigma_{3}$.

Figures 5 (a) and (b) show the orientations of the principal stresses that lie with a $95 \%$ confidence region for FMSI and LSIB respectively. The confidence intervals are determined using different error functions, and although both methods give rather similar results for the best-fitting values, the confidence intervals are quite different, with the FMSI method giving much larger confidence intervals. Similar large confidence regions found by FMSI are also noted by Hardebeck and Hauksson (2001) who conclude that these are too large, whereas the LSIB method gives more appropriate confidence intervals for their synthetic data set. However, Michael (1987) also states that where both possible fault planes are used, as is the case here, the confidence regions 
may be underestimated by LSIB.

In general, the individual rotations that describe the misfit between the observed fault planes for each focal mechanism and the models are around $5^{\circ}$, which might suggest that the assumption of uniform stress is a reasonable one. However, a some of solutions show much larger misfit rotations. In particular, the five earthquakes in northwest Scotland all show misfits of greater than $5^{\circ}$, and the Aberfoyle earthquake (2003) has a much larger misfit of $28^{\circ}$. This suggests that perhaps these events are not caused by the same stress field that appears to explain most of the other earthquakes.

To examine any spatial variation in misfit, I split the data into two geographic subsets: the five earthquakes in northwest Scotland; and all earthquakes in England and Wales along with the two events in southern Scotland. Best fitting stress tensors are calculated for both these subsets using both the FMSI and LSIB methods. The results are also listed in Table 2 and shown in Figure 5 (c) and (d).

The best-fitting stress tensors for the Scottish subset are now quite different to that found for England and Wales. The orientations of the principal stresses found for the latter remain close to the best fitting stress tensor for the whole data set, with northwest-southeast compression and southeastnorthwest extension. As previously noted, the plunge directions calculated by the LSIB method for $\sigma_{1}$ and $\sigma_{3}$ are closer to horizontal than those calculated by FMSI. The values of $R$ again suggest that the intermediate stress $\sigma_{2}$ is close to the average value of $\sigma_{1}$ and $\sigma_{3}$. The best fitting stress tensor for the Scottish data has a $\sigma_{1}$ orientation that is sub-vertical, with a near east-west $\sigma_{3}$. In this case, both FMSI and LSIB give very similar results. The 
1

3

4

5 6 Scottish observations and the model is less than $2^{\circ}$. for $\sigma_{1}$ and $\sigma_{2}$ shown in Figure 5 (d).

\section{Discussion}

8

value of $R$ calculated for the Scottish data suggests that $\sigma_{1}$ and $\sigma_{2}$ are very close in value and there is significant overlap in the $95 \%$ confidence regions

The overall misfits both the regional inversions are reduced from the misfit value for all the data. The largest individual minimum rotation between the

First order intraplate stresses depend mainly on the same forces that drive plate motion. This can result in a uniform stress field over large areas. In the UK, these forces are generated at the Mid-Atlantic ridge due to gravitational effects acting perpendicular to the spreading ridge, and, to a lesser extent, forces resulting from the collision of Africa with Europe. This is expected to result in a prevailing northwest to north-northwest orientation for $s_{H}$, the maximum horizontal compressional stress. The magnitude of the ridge push force depends on the distance from the divergent boundary. Estimates vary between 20-40 MPa, depending on the properties of the lithosphere. A number of authors, including Gölke and Coblentz (1996) have modelled tectonic stress in northwest Europe due to ridge push and continental collision. The predicted maximum horizontal stress orientation for the UK is consistently northwest southeast, which is good agreement with the inversion results found here for England and Wales.

Existing stress data for the British Isles and immediate offshore area from the World Stress Map 2008 (Heidbach et al., 2008) are shown in Figure 6. These $s_{H}$ orientations result from a variety of stress indicators including 
1 borehole breakouts, drilling induced fracturing and hydro-fracturing as well 2 as five focal mechanisms previously determined for British earthquakes. The 3 large bold symbols show the the $s_{H}$ orientations determined for Scotland and 4 England using the LSIB method. In general, the onshore observations for 5 England and Wales are very similar and show a northwest-southeast max6 imum compressive stress orientation which is consistent with the inversion 7 results for England and Wales. The values of $R$ determined for England and \& Wales suggests that the intermediate stress $\sigma_{2}$ is close to the average value 9 of $\sigma_{1}$ and $\sigma_{3}$. These results suggest that England and Wales can be best de10 scribed by a compressive strike-slip tectonic regime, where the intermediate

principal stress is vertical and the maximum and minimum principal stresses are horizontal. There may also be components of both thrust and normal faulting, as indicated by the sub-horizontal orientations of $\sigma_{1}$ and $\sigma_{3}$.

A second source of crustal stress in the UK is glacio-isostatic adjustment (GIA). Maximum ice thickness in northwest Scotland is estimated to be $1000 \mathrm{~m}$ (Ballantyne et al. , 1998), and there is a good correlation between the spatial extent of the seismicity in northwest Scotland and the region of maximum ice thickness, suggesting that this could be an important factor in the seismotectonics of the UK. Most of our understanding of the rates and patterns of post-glacial uplift in the UK has been determined from long-term estimates of sea-level changes which have been used to constrain quantitative models of isostatic adjustment (Shennan et al., 2006; Milne et al. , 2006). Uplift rates are around $2 \mathrm{~mm} / \mathrm{a}$ in Northern Britain, which will result in curvature dependent bending stress along the axis of the uplift. Stein et al. (1989) model the effect of a $1 \mathrm{~km}$ thick ice sheet and find lithospheric 
1

2 This deglaciation flexure should give rise to tensional stress acting in all

3 dirt

4 and compression in the unglaciated region. Directional dependence of the

5 focal mechanisms suggests that the stresses induced by GIA alone cannot be

6 the only driving force for earthquake activity.

7

stresses of a few tens of MPa, which is similar to that due to ridge-push. directions in the shallow part of the lithosphere under the deglaciated region

The inversion results for Scotland show near east-west extension with possible $\sigma_{1}$ and $\sigma_{2}$ directions lying in a north south band, and that the magnitudes of $\sigma_{1}$ and $\sigma_{2}$ are quite similar $(R>0.9)$. This would appear to be consistent with the suggested magnitudes for stresses due to ridge-push and post-glacial readjustment. Existing stress data for Scotland are sparse, with just two focal mechanisms found in Heidbach et al. (2008), so it is not possible to make a direct comparison with the results found here.

Both the FMSI and LSIB inversion methods give quite similar results for the orientations of the principal stresses, although the LSIB method gives directions for $\sigma_{1}$ and $\sigma_{3}$ for England and Wales that are closer to horizontal than those found by FMSI. The principal stress directions determined by both methods for the Scottish data are very similar. Similarly, the values of $R$ given by each method are close. The $95 \%$ confidence intervals given by both methods are quite different, with the FMSI method giving much larger confidence intervals. Hardebeck and Hauksson (2001) also note large confidence regions found by FMSI for a synthetic data set and conclude that these are too large. These authors also conclude that the LSIB method is more accurate for noisy data, as is likely to be the case here, and gives more appropriate confidence intervals. As a result, the LSIB results found here 
might be considered more reliable.

The clear difference in the stress inversion results between northwest Scotland and England and Wales suggests that the principal stress orientations in Scotland are modified by additional regional stress sources related to GIA. Numerical modelling may be a useful tool to quantify the full nature and extent of the coupling between these different forces and characterize the relative magnitude of horizontal strains from ridge push and GIA. However, comprehensive geodetic data is required to constrain such models. Recent research by Bradley et al. (2009) compares observed crustal velocities at permanent GPS stations in Britain with predictions from a model of glacio isostatic adjustment (Shennan et al., 2006). They find that the observed and predicted vertical velocities are highly correlated, suggesting that GIA is the dominant geodynamic process affecting vertical motions. In contrast, the motion of the Eurasian plate dominates the horizontal component, but after this is removed using a simple plate motion model, no coherent pattern of horizontal motion is observed at the current level of precision. These findings also add further weight to contribution of GIA to the seismotectonics of the northern Britain.

\section{Conclusions}

Focal mechanisms for earthquakes in the UK are dominantly strike-slip with northwest-southeast compression and northeast-southwest tension, or reverse, with northwest-southeast compression. In many cases there is also an oblique component to the slip. $\mathrm{P}$ and $\mathrm{T}$ axes from individual solutions are relatively well constrained in azimuth, though less so in dip, with P-axes ori- 
entation for most events clustering between north and north-west, indicating sub-horizontal compression. However, some spatial variation in P- and Taxes orientation is also apparent, with near north/northeast compression and east-west extension in northwest Scotland, changing to northwest-southeast compression in England and Wales.

Two different methods were used to esimate best-fitting stress tensors by inversion of the focal mechanism data: the FMSI method of Gephart and Forsyth (1984); and the LSIB method of Michael (1987). When considering all the data, both methods gave similar results, with a sub-horizontal $\sigma_{1}$ in a northwest direction. However, the differences in the P-axis orientations for focal mechanisms in northwest Scotland and the individual misfits for these events suggest that the stress field is not homogeneous.

Dividing the data into two regional subsets resulted in quite different bestfitting stress orienations and relative magnitudes. The inversion results for England and Wales show northwest-southeast compression and southeastnorthwest extension, consistent with existing stress data (Heidbach et al., 2008). The relative magnitude of the principal stresses, $R$ determined for England and Wales suggests that the intermediate stress $\sigma_{2}$ is close to the average value of $\sigma_{1}$ and $\sigma_{3}$. By contrast, the inversion results for northwest Scotland show near east-west extension with possible $\sigma_{1}$ and $\sigma_{2}$ directions lying in a north south band, and that the magnitudes of $\sigma_{1}$ and $\sigma_{2}$ are quite similar $(R>0.9)$.

The clear difference in the stress inversion results between northwest Scotland and England and Wales suggests that the principal stress orientations in Scotland are modified by additional regional stress sources. This might 
1 be explained by the flexure dependent stresses due to glacio-isostatic adjust2 ment, which result in a change to the expected principal stress orientations 3 in northwest Scotland.

\section{7. Acknowledgements}

$5 \quad$ Additional data used to locate earthquakes and determine a fault plane 6 solutions was provided by AWE Blacknest, IRIS/IDA and GEOFON. Project 7 IDA is a global network of broadband and very long period seismometers 8 operated by the Institute of Geophysics and Planetary Physics, Scripps In-

9 stitution of Oceanography, University of California, San Diego. I also thank

the two anonymous reviewers for their helpful comments on the manuscript.

This work is published with the permission of the Executive Director of the British Geological Survey (NERC).

\section{References}

Arrowsmith, S.J., Kendall, M., White, N., VanDecar, J., Booth, D.C. (2005). Seismic imaging of a hot upwelling beneath the British Isles. Geology, $33(5), 345-348$.

Angelier, J., (1984). Tectonic analysis of fault slip data sets. J. Geophys. Res., 89, 5835-5848.

Angelier, J., Mechler, P., (1977). Sur une méthode graphique de recherche des contraintes principales également utilisable en tectonique et en séismologie: la méthode des diedres droits. Bull. Soc. Géol. France, 19, 1309-1318. 
1 Assumpçao, M., (1981). The NW Scotland earthquake swarm of 1974. Geo2 phys. J. Roy. Astr. Soc., 67, 577-586.

s Ballantyne, C.K., McCaroll, D., Nesje, A., Dahl, S.O., Stone, J.O., 1998. The $4 \quad$ last ice sheet in North-West Scotland: reconstruction and implications. 5 Quaternary Science Reviews 17, 1149-1184.

6 Baptie, B., Ottemöller, L., Sargeant, S., Ford, G., O’Mongain, A., (2005). $7 \quad$ The Dudley Earthquake of 2002: A moderate sized earthquake in the UK. 8 Tectonophysics, 401 1-22.

Bluck, B., J., Gibbons, W., Ingham, J., K., (1992). Terranes. In: Cope, J., C., Ingham, J., K., Rawson, P., F., (eds), Atlas of Palaeogeography and Lithofacies. Geol. Soc. (London) Memoirs, 13, 1-4

Bott, M.H.P, (1959). The mechanics of oblique slip faulting , Geol. Mag., 96, $2,109-117$.

Bott, M.H.P., Bott, J.D.J., (2004). The Cenozoic uplift and earthquake belt of mainland Britain as a response to an underlying hot, low-density upper mantle. J. Geol. Soc. (London), 161, 19-29.

Bradley, S.L., Milne, G.A., Teferle, F.N., Bingley, R.M., Orliac, E.J., (2009). Glacial isostatic adjustment of the British Isles: new constraints from GPS measurements of crustal motion, Geophys. J. Int., 178, 2, 14-22.

Gephart, J.W., Forsyth, D.W., (1984). An Improved method for determining the regional stress tensor using earthquake focal mechanism data: application to the San Fernando earthquake sequence. J. Geophys. Res., 89(B11), 9305-9320. 
1 Gölke, M., Coblentz, D., (1996). Origins of the European regional stress field.

$2 \quad$ Tectonophysics, 266, 11-24.

3 Hardebeck, J.L., Hauksson, E., (2001). Stress orientations obtained from

$4 \quad$ earthquake focal mechanisms: what are appropriate uncertainty estimates?

$5 \quad$ Bull. Seismol. Soc. Am., 91, 2, 250-262.

6 Heidbach, O., Tingay, M., Barth, A., Reinecker, J., Kurfeß, D. and

7 Müller, B., (2008). The World Stress Map database release 2008 $8 \quad$ doi:10.1594/GFZ.WSM.Rel2008.

9 Heyburn, R., Bowers, D., Selby, N., Douglas, A., (2005). How deep was the

$10 \quad$ Dudley (UK) earthquake of 22 September 2002? J. Seismol., 9, 61-71.

11 King, G., (1980). A fault plane solution for the Carlisle earthquake, 26 De12 cember 1979. Nature, 286, 142-143.

Lisle, R.J., (1992). New method of estimating regional stress orientations: application to focal mechanism data of recent British earthquakes. Geophys. J. Int., 110, 276-282.

Lund, B., Townend, J., (2007). Calculating horizontal stress orientations with full or partial knowledge of the tectonic stress tensor. Geophys. J. Int., 170, 1328-1335.

McKenzie, D.P., (1969). The relationship between fault plane solutions for earthquakes and the direction of principal stresses. Bull. Seismol. Soc. Am., 59, 591-601. 
1 Main, I., D., Irving, D., Musson, R.M.W., Reading, A., (1999). Constraints

2 on the frequency-magnitude relation and maximum magnitudes in the UK

3 from observed seismicity and glacio-isostatic recovery rates. Geophys. J.

$4 \quad$ Int., $\mathbf{1 3 7}(2), 535-550$.

5 Marrow, P.C., Walker, A.B., (1988). LLeyn earthquake of 1984 July 19:

6 Aftershock sequence and focal mechanism. Geophys. J. Int., 92, 487-493.

7 Michael, A.J., (1987). Use of focal mechanisms fo determine stress: a control

$8 \quad$ study. J. Geophys. Res., 92(B1), 357-368.

9 Milne, G.A., Shennan, I., Youngs, B.A.R., Waugh, A.I., Teferle, F.N., Bin-

10 gley, R.M., Bassett, S.E., Cuthbert-Brown, C., Bradley, S.L., 2006. Mod-

11 elling the glacial isostatic adjustment of the UK region. Phil. Trans. Roy.

$12 \quad$ Soc. 364, 931-948.

Ottemöller, L., Thomas, C.W., (2007). Highland Boundary Fault Zone: Tectonic implications of the Aberfoyle earthquake sequence of 2003. Tectonophysics, 430, 83-95.

Ottemöller, L., Baptie, B., Smith, N., (2009). Source parameters for the 28 April $2007 M_{W} 4.0$ earthquake in Folkestone, United Kingdom. Bull. Seismol. Soc. Am., 99, 3, 1853-1867.

Pharaoh, T., Molyneux, S., Merriman, R., Lee, M., Verniers, J., (1993). The Caledonides of the Anglo-Brabant Massif reviewed. Geology Magazine, 130, 561-562. 
1 Redmayne, D.W., Musson, R.M.W., (1987). The Dunoon earthquake 2 of 16 September 1987. British Geological Survey Technical Report $3 \mathrm{WL} / \mathrm{GS} / 84 / 241$.

4 Ritchie, M.E.A., Musson, R.M.W., Woodcock, N.H., (1990). The Bishop's $5 \quad$ Castle earthquake of 2 April 1990. Terra Nova, 2, 390-400.

6 Sargeant, S., Ottemöller, L., Baptie, B. (2008). A Comparison of two Re7 cent Damaging Earthquakes in the UK. American Geophysical Union, Fall $8 \quad$ Meeting 2008, Abstract S23B-1885

Shennan, I., Bradley, S., Milne, G., Brooks, A., Bassett, S., Hamilton, S. (2006). Relative sea-level changes, glacial isostatic modelling and ice-sheet reconstructions from the British Isles since the Last Glacial Maximum. J. Quat. Sci., 21, 585-599.

Snoke, J., Munsey, J., Teague, A., Bollinger, G., (1984). A program for focal mechanism determination by combined use of polarity and P-SV amplitude ratio data. Earthquake Notes, 55, 3-15.

Stein, S., Cloetingh, S., Sleep, N.H., and Wortel, R., (1989). Passive margin earthquakes, stresses and rhelogy. In: S. Gregersen and P.W. Basham (Editors), Earthquakes at North-Atlantic Passive Margins: Neotectonics and Postglacial Rebound. Series C: Mathematical and Physical Sciences. Kluwer Academic Publishers, pp. 231-260.

Trodd, H., Warburton, P., Pooley, C.I., (1985). The Great British Earthquake of 1984 seen from afar. Geophys. J. Roy. Astr. Soc., 83, 809-812. 
1 Turbitt, T., Barker, E.J., Browitt, C.W.A., Howells, M., Marrow, P.C., Mus2 son, R.M.W., Newmark, R.H., Redmayne, D.W., Walker, A.B., Jacob, $3 \quad$ A.W.B., Ryan, E., Ward, V., (1985). The North-Wales Earthquake of 19 $4 \quad$ July 1984. J. Geol. Soc. (London), 142, 567-571.

5 Walker, A.B., (1991). The Jersey Earthquake of 30th April 1990. Ann. Bull. $6 \quad$ Soc. Jersiaise, 25, 3, 529-538.

7 Woodcock, N.H., Strachan, R.A., (2000). Geological History of Britain and $8 \quad$ Ireland, John Wiley and Sons. 


\section{Tables}

\begin{tabular}{|c|c|c|c|c|c|c|c|c|c|c|}
\hline Event & Year & Lat & Lon & Dep & $M_{L}$ & Strike & Dip & Rake & Locality & Source \\
\hline 1 & 1974 & 57.23 & -5.34 & 11 & 4.6 & 52 & 78 & -6 & Kintail & Assumpçao (1981) \\
\hline 2 & 1979 & 55.03 & -2.82 & 4 & 4.8 & 29 & 43 & -6 & Carlisle & King (1980) \\
\hline 3 & 1984 & 52.43 & -3.22 & 11 & 3.3 & 211 & 88 & 20 & Felindre & \\
\hline 4 & 1984 & 52.96 & -4.38 & 21 & 5.4 & 290 & 65 & -150 & Lleyn & Trodd et al. (1985) \\
\hline 5 & 1984 & 52.96 & -4.38 & 21 & 4.3 & 306 & 40 & -82 & Lleyn & Marrow and Walker (1988) \\
\hline 6 & 1986 & 56.04 & -4.91 & 6 & 3.5 & 35 & 60 & -30 & Dunoon & Redmayne and Musson (1987) \\
\hline 7 & 1990 & 52.44 & -3.03 & 14 & 5.1 & 182 & 60 & 19 & Bishops Castle & Ritchie et al. (1990) \\
\hline 8 & 1990 & -49.10 & -3.67 & 8 & 3.5 & 232 & 82 & 55 & Jersey & Walker (1991) \\
\hline 9 & 1992 & 52.50 & -0.19 & 11 & 3.3 & 213 & 36 & 54 & Peterborough & \\
\hline 10 & 1992 & 53.13 & -4.40 & 11 & 3.5 & 358 & 68 & 57 & Caernavon & \\
\hline 11 & 1993 & 54.21 & -2.86 & 8 & 3.1 & 184 & 46 & 54 & Grange-Over-Sands & \\
\hline 12 & 1994 & 52.54 & -3.44 & 22 & 3.1 & 27 & 61 & 52 & Newtown & \\
\hline 13 & 1996 & 52.79 & -2.74 & 10 & 3.4 & 351 & 52 & -27 & Shrewsbury & \\
\hline 14 & 1996 & 52.32 & -3.33 & 14 & 3.0 & 43 & 32 & 50 & Llandrindod & \\
\hline 15 & 1996 & 50.00 & -5.58 & 8 & 3.8 & 350 & 50 & -4 & Penzance & \\
\hline 16 & 1999 & 55.40 & -5.24 & 19 & 4.0 & 42 & 80 & 2 & Arran & \\
\hline 17 & 1999 & 53.20 & -4.35 & 16 & 3.2 & 191 & 76 & 4 & Caernavon & \\
\hline 18 & 1999 & 51.97 & -3.57 & 14 & 3.6 & 358 & 46 & -27 & Sennybridge & \\
\hline 19 & 2000 & 52.28 & -1.61 & 14 & 4.2 & 183 & 61 & -8 & Warwick & \\
\hline 20 & 2001 & 55.10 & -3.64 & 12 & 3.0 & 351 & 87 & 20 & Dumfries & \\
\hline 21 & 2001 & 51.70 & -3.25 & 6 & 3.1 & 188 & 63 & -62 & Bargoed & \\
\hline 22 & 2001 & 52.85 & -0.86 & 12 & 4.0 & 185 & 85 & -2 & Melton Mowbray & \\
\hline 23 & 2002 & 51.70 & -3.26 & 5 & 3.0 & 185 & 65 & -79 & Bargoed & \\
\hline 24 & 2002 & 52.53 & -2.15 & 14 & 4.7 & 9 & 86 & -2 & Dudley & Baptie et al. (2005) \\
\hline 25 & 2002 & 53.48 & -2.20 & 3 & 3.9 & 21 & 0 & 0 & Manchester & \\
\hline 26 & 2003 & 56.17 & -4.43 & 4 & 3.2 & 244 & 66 & -33 & Aberfoyle & Ottemöller and Thomas (2007) \\
\hline 27 & 2005 & 53.25 & -3.83 & 10 & 3.3 & 184 & 78 & -22 & Conwy & \\
\hline 28 & 2006 & 55.09 & -3.63 & 7 & 3.5 & 350 & 88 & 10 & Dumfries & \\
\hline 29 & 2006 & 56.96 & -5.61 & 3 & 2.8 & 62 & 81 & 5 & Mallaig & \\
\hline 30 & 2007 & 51.10 & 1.17 & 5 & 4.3 & 326 & 72 & -45 & Folkestone & Ottemöller et al. (2009) \\
\hline 31 & 2008 & 53.40 & -0.33 & 18 & 5.2 & 91 & 66 & 150 & Lincoln & Sargeant et al. (2008) \\
\hline
\end{tabular}

Table 1: Focal mechanism parameters for the earthquakes used in this study. Solutions that have previously been published are indicated by the references in the final column. 


\begin{tabular}{llllllll} 
Region & Method & $\sigma_{1}$ & $\sigma_{2}$ & $\sigma_{3}$ & $R$ & Misfit & $s_{H}$ \\
\hline \multirow{2}{*}{ All } & LSIB & 331,5 & 104,83 & 241,5 & 0.48 & 0.144 & 153 \\
& FMSI & 340,25 & 92,39 & 226,41 & 0.6 & 5.943 & 151 \\
\multirow{4}{*}{ Scotland } & LSIB & 162,71 & 14,17 & 281,9 & 0.97 & 0.004 & 168 \\
& FMSI & 175,68 & 11,21 & 279,6 & 0.9 & 0.878 & 1 \\
\multirow{5}{*}{ England } & LSIB & 320,3 & 69,80 & 229,9 & 0.44 & 0.097 & 139 \\
& FMSI & 336,31 & 96,40 & 221,35 & 0.5 & 4.747 & 144 \\
\hline
\end{tabular}

Table 2: Inversion Results from both the FMSI method of Gephart and Forsyth (1984) and the LSIB method of Michael (1987) for all data and for Scottish and English events. Orientations of the best-fitting principal stresses are given by trend and plunge angles. Also shown is the orientation of the maximum horizontal compressive stress, $s_{H}$ calculated following Lund and Townend (2007) 


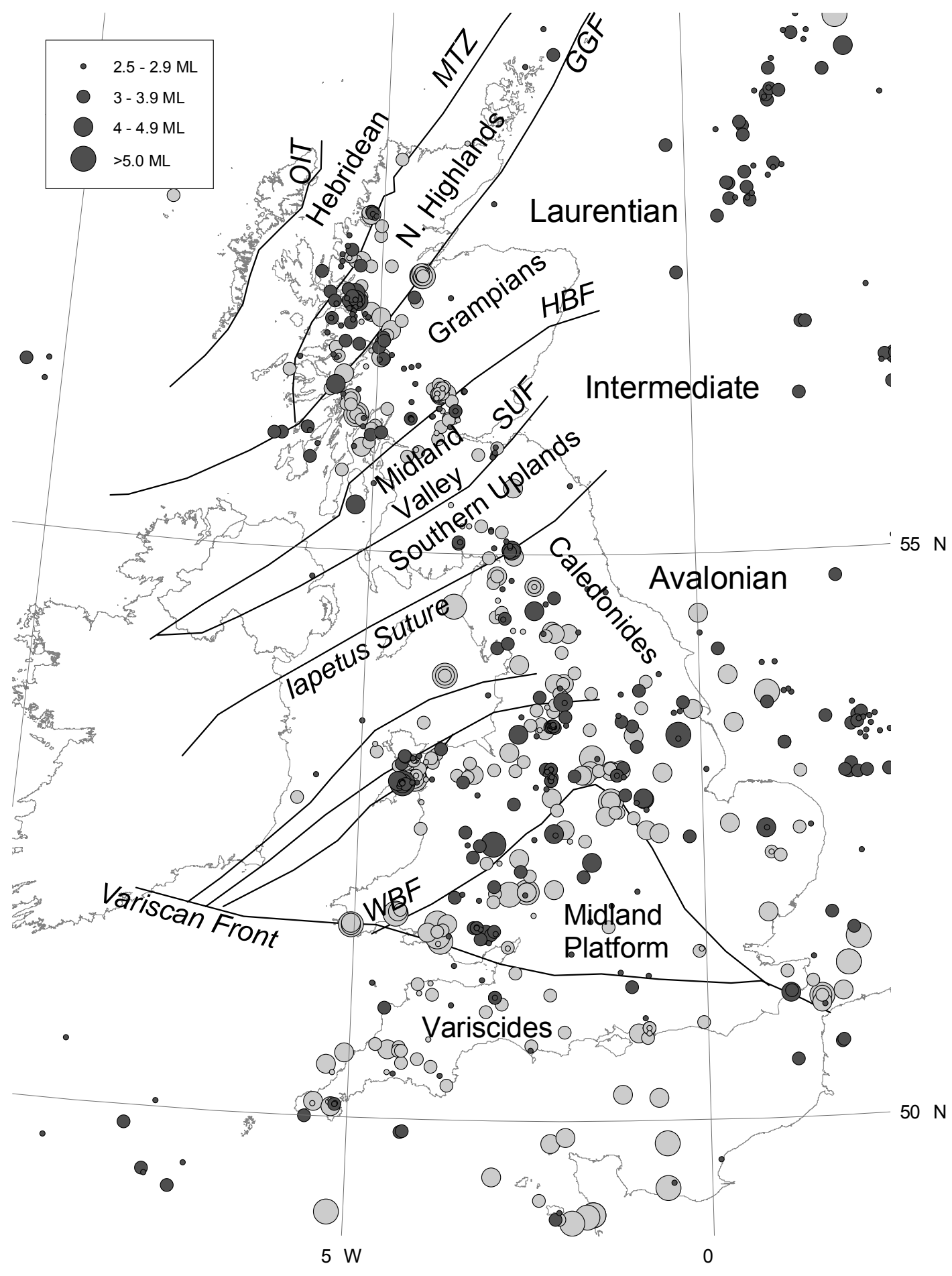

26

Figure 1: Instrumental (dark grey) and historical (light gray) seismicity of the British Isles from the British Geological Survey earthquake catalogue (Musson , 1996). Earthquake symbols are scaled by magnitude. Geological terranes after Bluck et al. (1992) are also shown. Major faults corresponding to terrane boundaries are abbreviated as follows: Outer Isles Thrust (OIT); Moine Thrust (MTZ); Great Glen Fault (GGF); Highland Boundary Fault (HBF); Southern Uplands Fault (SUF); Welsh Borderland Fault System (WBF). 

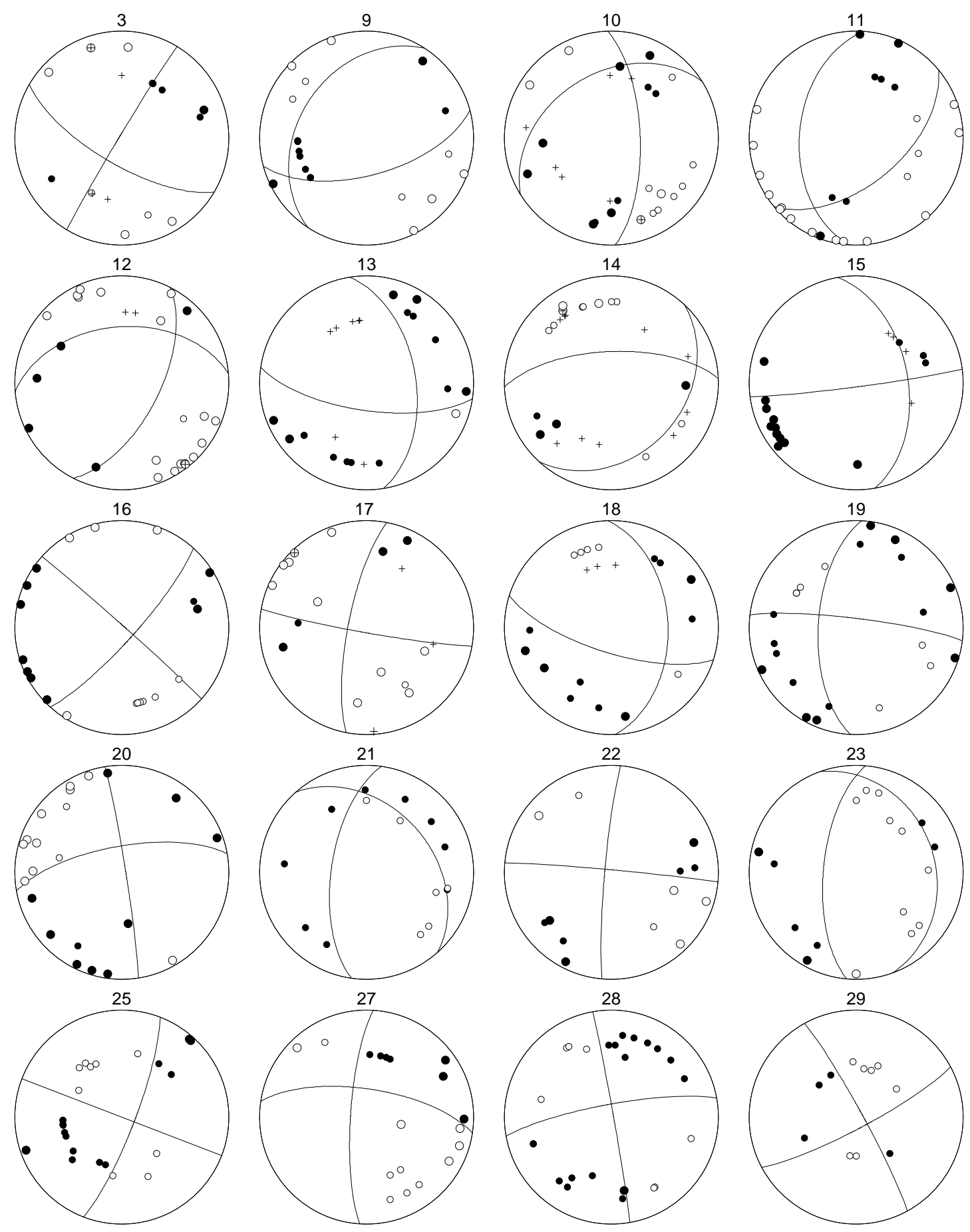

Figure 2: Focal mechanisms determined for the smaller earthquakes used in this study without any previous solutions and calculated using the grid search method of Snoke et al. (1984). Numbers correspond to the event numbers given in Table 1. Black circles indicate compression, white circles dilatation and crosses emergent arrivals. 


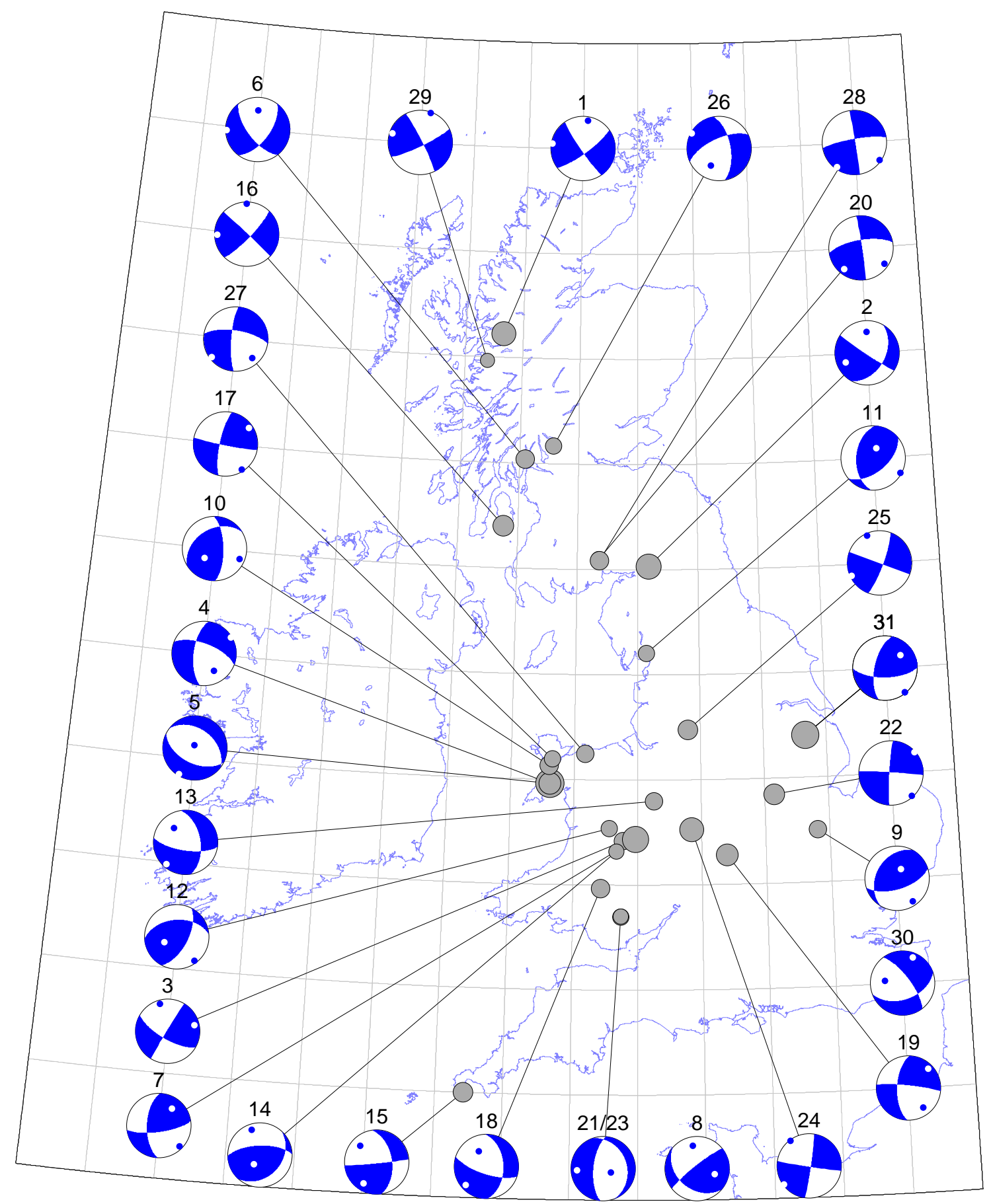

Figure 3: Focal mechanisms for all earthquakes used in this study. Numbers correspond to the event numbers given in Table 1. Only the focal mechanism for the Bargoed earthquake 28

of 2001 is shown. P- and T- axes are indicated by the black and white circles respectively. 


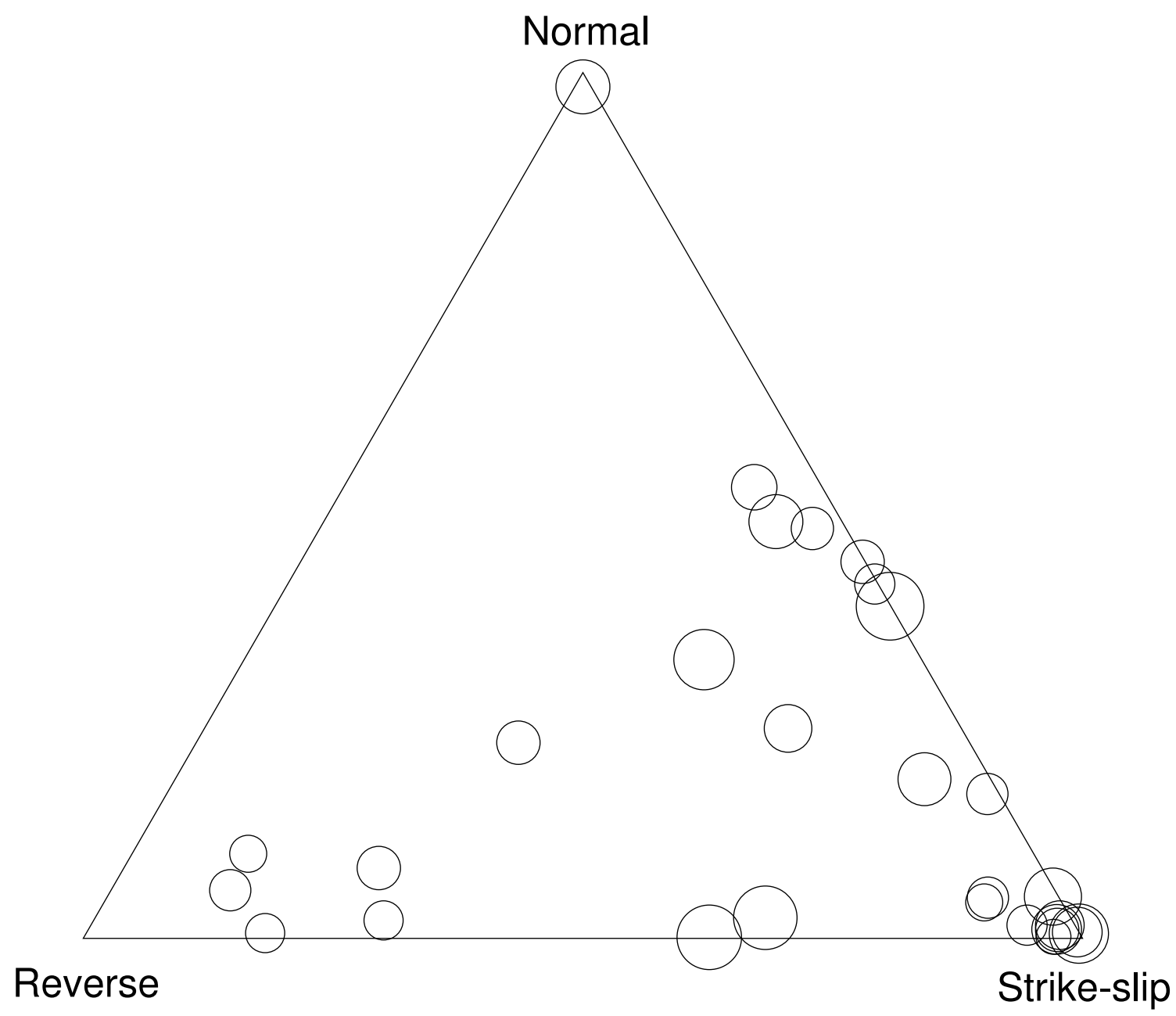

Figure 4: Ternary diagram showing the different components of slip for UK earthquakes. 

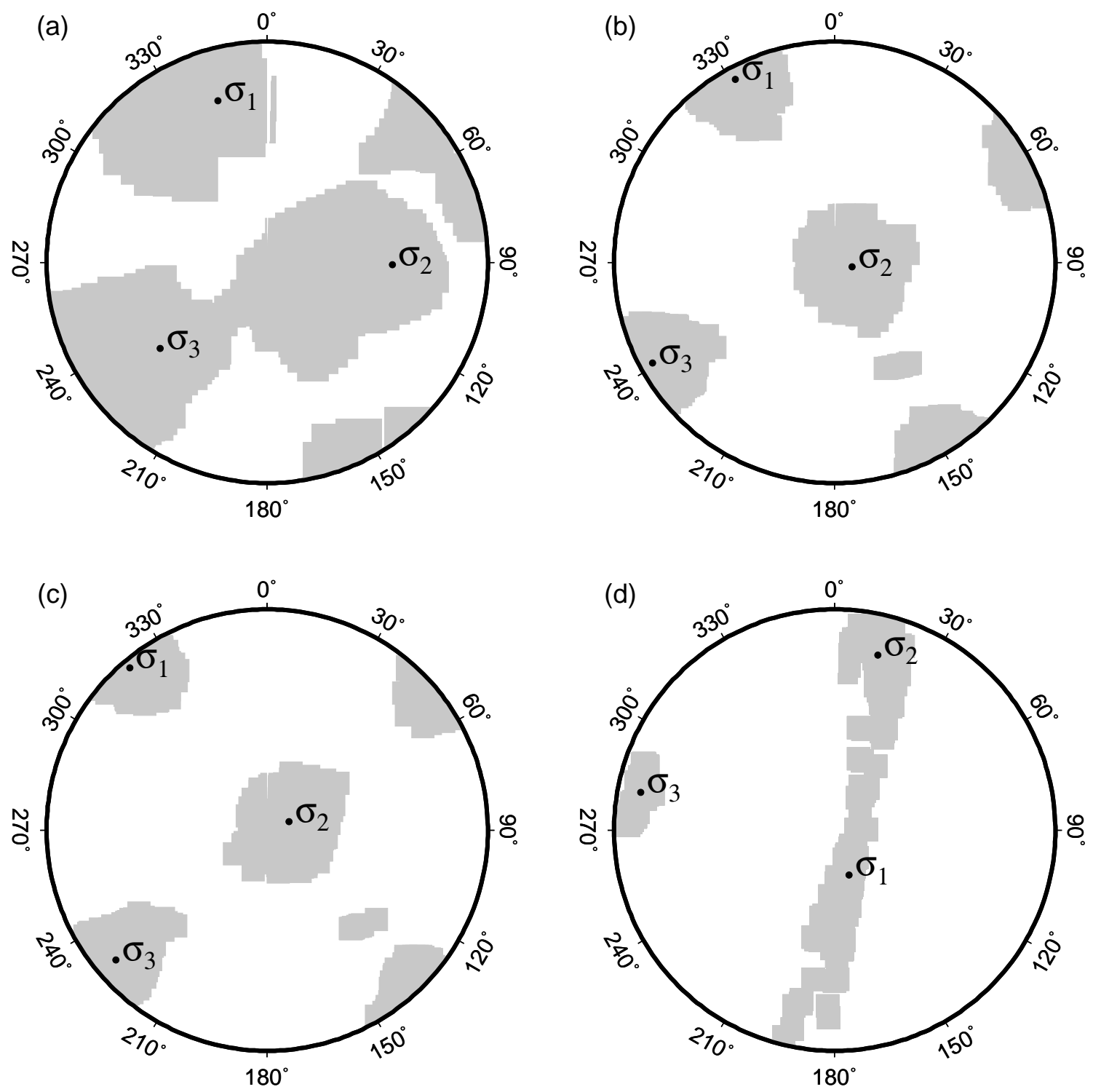

Figure 5: Best fitting stress tensors obtained for: (a) the FMSI method using all focal mechanisms; (b) the LSIB method using all focal mechanisms; (c) the LSIB method using focal mechanisms for England and Wales only; (d) the LSIB method using focal mechanisms for northwest Scotland only. The $95 \%$ confidence intervals are indicated by the shaded areas. 


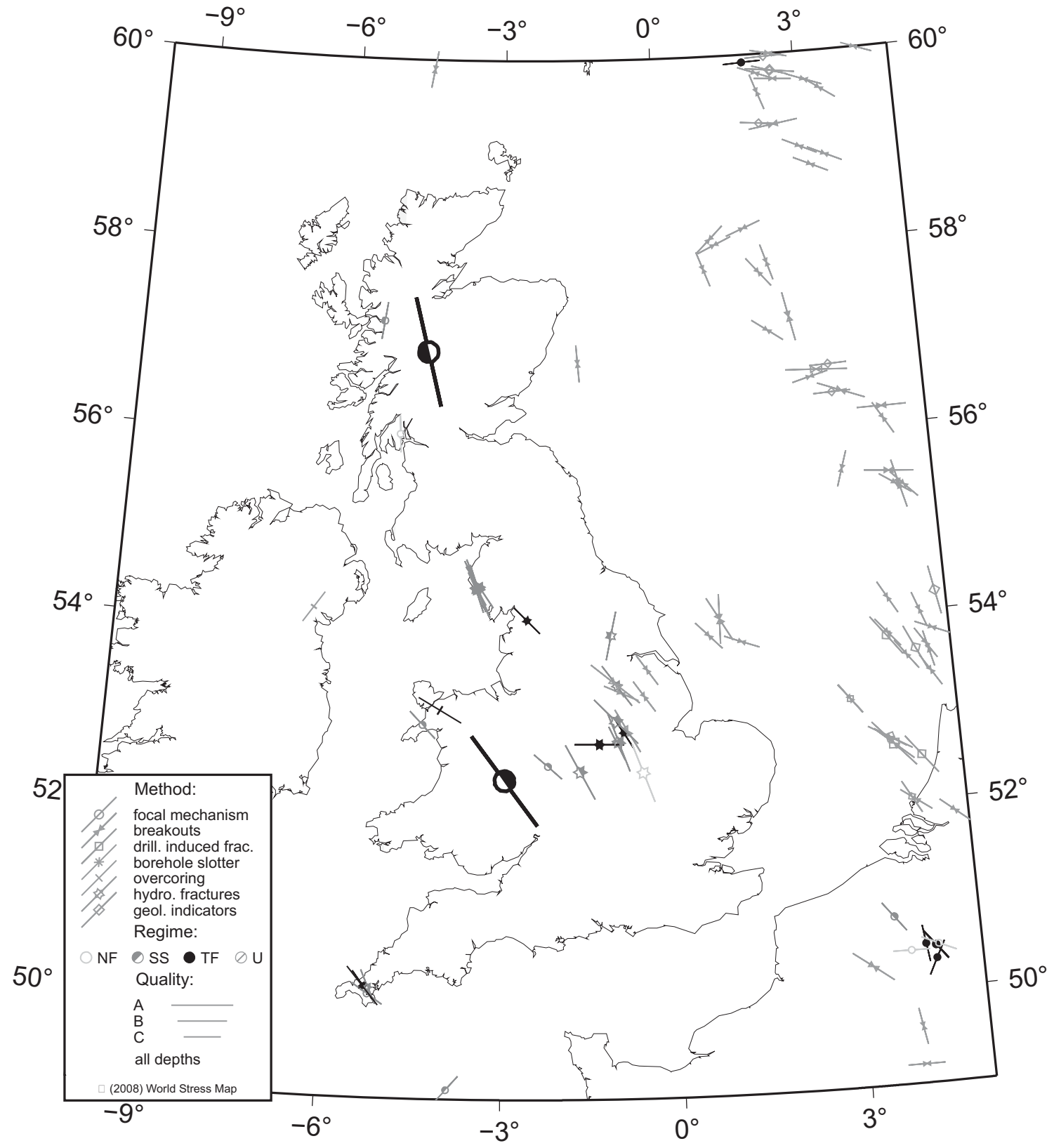

Figure 6: Stress data for the British Isles from the World Stress Map 2008 release (Heidbach et al., 2008). Different stress indicators and tectonic regimes are indicated by the symbols shown in the legend: $\mathrm{NF}=$ normal faulting; $\mathrm{TF}=$ thrust faulting; $\mathrm{SS}=$ strike-slip; and $\mathrm{U}=$ unknown. Line length is proportional to WSM data quality (A,B,C). The large bold symbols show the $s_{H}$ orientations determined for Scotland and England using the LSIB method. 